\title{
ETIKA LINGKUNGAN MASYARAKAT PESISIR DI KOTA SINGARAJA
}

\author{
Khairun Nissa ${ }^{1}$, Putu Indra Christiawan ${ }^{2 *}$
}

Prodi Pendidikan Geografi, Universitas Pendidikan Ganesha, Indonesia

\section{A R T I C L E IN F O}

Article history:

Received 19 Agustus 2018

Received in revised form

6 November 2018

Accepted 12 October 2018

Available online 30

November 2018

\section{Kata Kunci:}

Etika

Lingkungan

Masyarakat

Pesisir

Keywords:

Ethics

Environmental

Communities

Coastal

\begin{abstract}
A B S T R A K
Penelitian ini dilaksanakan di Kota Singaraja. yang bertujuan untuk : (1) mendeskripsikan pengetahuan masyarakat pesisir tentang kebersihan pantai di Kota Singaraja, (2) menjelaskan perilaku masyarakat pesisir terhadap pantai di Kota Singaraja, dan (3) menganalisis hubungan pengetahuan lingkungan dengan perilaku masyarakat pesisir terhadap pantai di Kota Singaraja. Metode yang digunakan adalah Simple Random Sampling. Rancangan penelitian menggunakan deskriptif kualitatif dan korelasional. Penelitian ini melibatkan 82 responden yang tersebar di 3 kelurahan yaitu: kelurahan Baktiserage, Kp. Bugis, dan Penarukan. Data diperoleh dengan melakukan observasi, wawancara, kuisioner, pencatatan dokumen, dan kepustakaan. Hasil penelitian menunjukan bahwa (1) pengetahuan masyarakat pesisir tentang kebersihan pantai di Kota Singaraja terkategori tinggi dengan capaian skor rata-rata sebesar 36,85. (2) perilaku masyarakat pesisir terhadap pantai di Kota Singaraja terkategori sedang dengan capaian skor ratarata sebesar 28,23. (3) hubungan pengetahuan lingkungan dengan perilaku masyarakat pesisir terhadap pantai di Kota Singaraja di analisis melalui korelasi Product Moment yakni di dapat hasil $r=0,433381924$ sedangkan $r$ pada tabel dengan taraf signifikasi $5 \%$ yaitu $r=0,220$. Berarti $r_{\text {hitung }}>r_{\text {tabel }}$ maka Hipotesis diterima. Sehingga Terdapat hubungan positif dan signifikan antara pengetahuan lingkungan dengan perilaku masyarakat pesisir dalam menjaga kebersihan lingkungan.
\end{abstract}

A B S T R A C T

The research was conducted in the city of Singaraja. which aims to: (1) describes coastal community knowledge about coastal cleanliness in Singaraja Town, (2) explains coastal community behavior toward beach in Singaraja Town, and (3) analyzes environmental knowledge relation with coastal community behavior toward beach in Singaraja Town. The method used is Simple Random Sampling. The research design uses qualitative and correlational descriptive. This research involves 82 respondents spread in 3 urban villages namely: kelurahan Baktiserage, Kp. Bugis, and Penarukan. The data were obtained by observation, interview, questionnaire, document recording, and bibliography. The results showed that (1) the knowledge of coastal communities about coastal cleanliness in Singaraja City is categorized as high with average score achievement of 36.85. (2) the behavior of coastal communities against the beach in Singaraja Town is categorized with average achievement score of 28.23. (3) the relationship of environmental knowledge with the behavior of coastal communities to the beach in Singaraja City is analyzed through Product Moment correlation which is in can result $=0.433381924$ while $r$ in table with $5 \%$ significance level is $r=0,220$. Means rhitung > rtabel then Hypothesis accepted. So there is a positive and significant relationship between environmental knowledge with the behavior of coastal communities in maintaining cleanliness of the environment. 



\section{Pendahuluan}

Lingkungan hidup, penduduk, dan kebudayaan saling terkait dan saling ketergantungan satu sama lain. Rusdiana A (2015) mengungkapkan Fakta menunjukkan manusia adalah makhluk yang mempunyai ketergantungan paling besar terhadap lingkungannya.Keterkaitan manusia lingkungan kebudayaan merupakan satu garis yang tidak bisa diputus. Hidup mati manusia sangat tergantung kepada lingkungan hidupnya. Kehidupan manusia juga dibentuk dan dipengaruhi dari lingkungannya (Handoyo, Eko., 2015). Ketergantungan seperti itu yang membuat manusia harus paham dalam menjaga lingkungan, untuk mengatur kondisi lingkungan agar tetap seimbang, maka munculah etika. Etika merupakan suatu kaidah, norma dan aturan yang berisikan perintah untuk mengatur perilaku manusia. Mengacu pada pemahaman tersebut maka etika lingkungan hidup pada hakekatnya membicarakan mengenai norma dan kaidah moral yang mengatur perilaku manusia dalam berhubungan dengan alam, serta nilai dan prinsip moral yang menjiwai perilaku manusia dalam berhubungan dengan alam tersebut .

Etika lingkungan hidup berbicara mengenai perilaku manusia terhadap alam dan juga relasi diantara semua kehidupan alam semesta, yaitu antara manusia dengan manusia yang mempunyai dampak pada alam, dan antara manusia dengan makhluk hidup yang lain atau dengan alam secara keseluruhan, termasuk di dalamnya kebijakan politik dan ekonomi yang mempunyai dampak langsung atau tidak langsung terhadap alam. Kurangnya kesadaran dan pemahaman masyarakat tentang kebijakan kepesisiran, tingkat pendidikan masyarakat yang rendah, watak masyarakat, serta tekanan biaya hidup menyebabkan masyarakat pesisir sering melakukan perusakan lingkungan pesisir (Pinto Zulmiro, 2015).

Rendahnya etika lingkungan umumnya ditenggarai karena rendahnya pengetahuan yang dimiliki terkait dengan lingkungan hidup. Menurut Wesnawa (2010) permasalahan lingkungan adalah masalah moral, persoalan perilaku manusia. Lingkungan bukan semata-mata permasalahan teknis. Krisis global yang terjadi sekarang ini adalah persoalan moral, krisis moral secara global, untuk itu perlu etika dan moralitas untuk mengatasinya. Berbagai kasus lingkungan yang muncul banyak bersumber dari perilaku manusia. Menurut Hermawan dan Roesman (2008) menyatakan sudah bukan rahasia lagi sampah di Indonesia sudah menjadi masalah yang serius. Tumpukan sampah banyak ditemui pada lokasi-lokasi pinggiran perairan, terutama sekitar pantai. Hal ini dapat ditemukan di sepanjang pantai kawasan Kota Singaraja. Astono Widyo (2010) mengungkapkan bahwa Problem sanitasi yang dilandasi faktor geografis dan topografi khas wilayah pesisir sering kali diperparah dengan pemukiman penduduk yang tidak mengacu pada tata ruang yang be-nar. Faktor utamanya disebabkan oleh sistem kepercayaan dan norma di lingkungan tersebut masih menganggap bahwa buang sampah sembarangan itu merupakan hal yang biasa-biasa saja. Sampai saat ini belum ada tindak lanjut untuk mengatasi masyarakat yang membuang sampah di pantai. Sehingga penting untuk diteliti lebih lanjut mengenai perilaku masyarakat pesisir Kota Singaraja, dari permasalahan tersebut 
maka judul yang sesuai dengan penelitian ini adalah Etika Lingkungan Masyarakat Pesisir Di Kota Singaraja.

Berdasarkan latar belakang yang telah dikemukakan diatas maka adapun rumusan masalah sebagai berikut: (1) Bagaimana pengetahuan masya- rakat pesisir terhadap kebersihan pantai di Kota Singaraja? (2) Bagaimana perilaku masyarakat pesisir terhadap pantai di Kota Singaraja? (3) Bagaimana hubungan pengetahuan dengan perilaku masyarakat pesisir terhadap kebersihan pantai di Kota Singaraja?

Tujuan yang ingin dicapai dalam penelitian ini adalah sebagai berikut: (1) Mendeskripsikan pengetahuan masyarakat pesisir di Kota Singaraja; (2) Menjelaskan perilaku masyarakat pesisir terhadap pantai di Kota Singaraja; (3) Menjelaskan hubungan pengetahuan lingkungan dengan perilaku masyarakat pesisir terhadap pantai di Kota Singaraja

\section{Metode}

Rancangan penelitian juga memberi arah tentang sampel penelitian, pengumpulan data dan teknik analisa data (Sriartha, 2004). Rancangan penelitian yang digunakan dalam penelitian ini adalah metode deskriptif dan korelasional. Menurut Sukmadinata (2011) penelitian deskriptif ditujukan untuk mendeskripsikan atau menggambarkan fenomena-fenomena yang ada, baik fenomena yang bersifat alamiah atau rekayasa manusia, secara deskriptif pengumpulan data dan informasi untuk memberikan gambaran atau penegasan suatu konsep atau gejala dan menjawab pertanyaan- pertanyaan. Rancangan penelitian ini akan mendeskripsikan tentang (1) Pengetahuan masyarakat pesisir di Kota Singaraja, (2) Perilaku masyarakat pesisir di pantai Kota Singaraja. Penelitian ini juga menggunakan korelasional yaitu suatu analisis yang ditujukan untuk mengetahui hubungan atau korelasi antara dua variabel atau lebih. Sehingga yang dikorelasikan dalam penelitian ini untuk menganalisis hubungan pengetahuan lingkungan dengan perilaku masyarakat pesisir di kawasan pantai Kota Singaraja. Daerah yang dijadikan sebagai lokasi penelitian adalah kawasan pesisir yang ada di Kota Singaraja.

Populasi wilayah dalam penelitian ini adalah lingkungan/dusun yang berbatasan langsung dengan pantai di Kota Singaraja secara administrasit, maka diperoleh data tentang jumlah penduduk yaitu sebesar 7532 KK yang tersebar di 13 lingkungan/ dusun yang berbatasan langsung dengan pantai Kota Singaraja. Penentuan sampel area ditentukan dengan teknik Purposive. Secara sengaja dipilih pantai yang berada di Kelurahan/desa Baktiseraga, Kp. Bugis, dan Penarukan. Dikarenakan menurut observasi awal 3 kelurahan/ desa tersebut masih memiliki masalah sampah. Pantai tersebut berada di bagian barat, tengah, dan timur Kota Singaraja. Tujuannya untuk membandingkan perilaku masyarakat pesisir di setiap wilayah.

Penentuan sampel responden mengacu pada ketentuan yang dikemukakan (Arikunto, 2011), sebagai ancar-ancar apabila subjeknya kurang dari 100 orang lebih baik keseluruhan populasi digunakan sebagai sampel, sehingga disebut penelitian populasi. Selanjutnya jika subjeknya lebih besar dari 100 dapat diambil sampel 5-10\% 
atau $15-20 \%$ atau lebih tergantung dari peneliti, dilihat dari tingkat homogenitas dan luasnya wilayah pengamatan dari setiap subyek. Mengingat jumlah populasi lebih dari 100, maka sampel yang digunakan sebanyak 5\% dari populasi yaitu sebanyak 82 responden.

Pengumpulan data dalam penelitian ini dikelompokkan menjadi 2 yaitu data primer dan data sekunder. Teknik pengumpulan data yang digunakan adalah observasi lapangan, wawancara terstruktur, pencatatan dokumen, dan kepustakaan. Analisis data untuk menentukan signifikansi lingkungan dari pertanyaan faktual pada tabel frekuensi yang menunjukkan jumlah dan persentase dari total responden. Informasi deskriptif juga disajikan dalam tabel Skala Likert untuk menilai pengetahuan dan perilaku lingkungan responden yang diuraikan dengan pendekatan geografi, yaitu pendekatan spasial dengan menekankan pada kekhususan ruang, sehingga nampak jelas variasi ekspresi keruangan lingkungan masyarakat pesisir di Kota Singaraja. Setelah dibuatkan hipotesis asosiatif, statistiknya dapat menggunakan Pearson Product Moment yang digunakan untuk menganalisis hubungan antara dua variabel dari sumber data yang sama. Mengkorelasikan antara pengetahuan masyarakat pesisir sebagai variabel bebas (X) dan perilaku masyarakat pesisir sebagai variabel terikat (Y). Kriteria dalam menguji hipotesis dengan analisis korelasi yaitu Ha diterima bila $r$ hitung lebih besar dari $r$ tabel.

\section{Hasil dan Pembahasan}

\subsection{Tingkat Pengetahuan Masyarakat Pesisir terhadap Etika Lingkungan}

Pendidikan menjadi hal yang pokok dalam mempengaruhi perilaku dalam menjaga lingkungan. Selain itu, untuk meningkatkan mutu lingkungan, pendi- dikan mempunyai peran yang sangat penting. Pengetahuan merupakan keseluruhan pemikiran, gagasan, ide, konsep dan pemahaman terhadap suatu objek tertentu. Pengetahuan sebagian besar diperoleh melalui mata dan telinga yang kemudian diingat kembali menjadi suatu materi atau rangsangan yang diterima sebelumnya.

Pengetahuan masyarakat pesisir tentang kebersihan pantai merupakan pemahaman yang dimiliki tentang suatu keadaan yang mengharuskan untuk masyarakat dalam menjaga lingkungannya. Hal tersebut juga berhubungan dengan etika lingkungan masyarakat di wilayah pesisir Kota Singaraja.

Data yang akan dianalisis diperoleh dengan kuesioner yang meliputi tes tentang pengetahuan etika lingkungan masyarakat pesisir. Kuesioner tersebut terdapat 10 pertanyaan mengenai pengetahuan dasar tentang etika lingkungan. Masing-masing pertanyaan memiliki bobot yang berbeda pada setiap jawaban dengan rentangan nilai 1 sampai 5 . Kemudian hasil penjumlahan setiap bobot yang didapat dikelompokkan ke dalam 3 kategori menurut (Arikunto, 2011) yaitu :
a. $10-23=$ Rendah
b. $24-36=$ Sedang
c. $37-50=$ Tinggi

Skor hasil tingkat pengetahuan lingkungan masyarakat pesisir di Kota Singaraja dapat dilihat pada Tabel 1. 
Tabel 1. Hasil Tingkat Pengetahuan Lingkungan Masyarakat Pesisir di Kota Singaraja

\begin{tabular}{|c|c|c|c|c|c|c|c|}
\hline \multirow[b]{2}{*}{$\mathbf{N}$} & \multirow{3}{*}{$\begin{array}{c}\text { Kelurahan/De } \\
\text { (2) }\end{array}$} & \multirow{2}{*}{$\begin{array}{l}\mathbf{N} \\
\%\end{array}$} & \multicolumn{3}{|c|}{ Kategori } & \multirow[b]{2}{*}{ Tot } & \multirow{2}{*}{$\begin{array}{l}\text { Rat } \\
\text { a- }\end{array}$} \\
\hline & & & Renda & Sedang & Tinggi & & \\
\hline ( & & (3) & (4) & (5) & (6) & (7) & (8) \\
\hline \multirow[b]{2}{*}{1.} & \multirow{2}{*}{$\begin{array}{l}\text { Baktiseraga } \\
\text { (Pantai }\end{array}$} & $\mathrm{N}$ & 3 & 11 & 22 & 36 & 36,75 \\
\hline & & $\%$ & 8,33 & 30,55 & 61,11 & 100 & 33,24 \\
\hline \multirow[b]{2}{*}{2.} & \multirow{2}{*}{$\begin{array}{l}\text { Kampung Bugis } \\
\text { (Ex. Pelabuhan) }\end{array}$} & $\mathrm{N}$ & 1 & 14 & 14 & 29 & 36,52 \\
\hline & & $\%$ & 3,45 & 48,275 & 48,275 & 100 & 33,03 \\
\hline \multirow{4}{*}{3.} & \multirow{2}{*}{$\begin{array}{l}\text { Penarukan } \\
\text { (Pantai }\end{array}$} & $\mathrm{N}$ & 2 & 3 & 12 & 17 & 37,29 \\
\hline & & $\%$ & 11,76 & 17,65 & 70,59 & 100 & 33,73 \\
\hline & \multirow[b]{2}{*}{ Jumlah } & $\mathbf{N}$ & 6 & 28 & 48 & 82 & 36,85 \\
\hline & & $\%$ & 7,32 & 34,15 & 58,54 & 100 & 100 \\
\hline
\end{tabular}

Berdasarkan Tabel 1. dapat diketahui pengetahuan masyarakat pesisir tentang etika lingkungan di wilayah pesisir Kota Singaraja dari 3 Kelurahan/Desa. Tingkat pengetahuan masyarakat pesisir tentang kebersihan pantai di kelurahan Baktiseraga yaitu terkategori sedang sebesar 30,55\%, dan kategori tinggi sebesar 61,11\%, pada Kelurahan Kp. Bugis kategori sedang dan tinggi sama yaitu sebesar 48,275\%, dan pada Kelurahan Penarukan yaitu kategori sedang sebesar 17,65\% dan terkategori tinggi sebesar 70,59\%. Secara umun pengetahuan masyarakat pesisir terhadap kebersihan pantai di Kota Singaraja terkategori tinggi dengan capaian skor rata-rata sebesar 36,85. Berarti masyarakat pesisir sudah banyak yang tahu mengenai kebersihan lingkungan, namun pengetahuan saja tidak cukup karena perlu dibuktikan lewat perilaku, sehingga perlu diteliti juga perilakunya

\subsection{Perilaku Masyarakat Pesisir terhadap Kebersihan Pantai di Kota Singaraja}

Perilaku merupakan tindakan atau aktivitas dari manusia itu sendiri yang mempunyai bentangan yang sangat luas. Perilaku juga merupakan respon atau reaksi seseorang terhadap rangsangan atau stimulus dari luar. Perilaku masyarakat dalam menjaga lingkungan harus diterapkan sejak dini. Mengingat berbagai masalah lingkungan sering terjadi seperti banyaknya sampah dan tidak adanya pembeda antara sampah organik dan non-organik. Keberadaan sampah di pantai dapat menimbulkan dampak negatif. Dampak negatif yang terlihat dari permasalahan lingkungan walaupun masih dalam taraf kecil namun sangat berpengaruh terhadap lingkungan pantai dari segi estetika.

Data dianalisis dengan analisis deskriptif kualitatif. Berupa kuisioner yang disebar ke responden berupa 10 butir soal. Berikut hasil kuisioner mengenai perilaku masyarat pesisir. 
Tabel 2. Skor Hasil Perilaku Masyarakat Pesisir terhadap Pantai di Kota Singaraja

\begin{tabular}{|c|c|c|c|c|c|c|c|}
\hline \multirow[t]{2}{*}{ No } & \multirow{3}{*}{$\begin{array}{c}\text { Kelurahan / } \\
\text { (2) }\end{array}$} & \multirow{2}{*}{$\begin{array}{l}\mathrm{N} \\
\%\end{array}$} & \multicolumn{3}{|c|}{ Kategori } & \multirow[t]{2}{*}{ Total } & \multirow{2}{*}{$\begin{array}{c}\text { Rata - } \\
\text { rata }\end{array}$} \\
\hline & & & Rendah & Sedang & Tinggi & & \\
\hline (1) & & (3) & (4) & (5) & (6) & (7) & (8) \\
\hline \multirow{3}{*}{1.} & Baktiserag & $\mathrm{N}$ & 4 & 10 & 3 & 17 & 28,11 \\
\hline & $\mathrm{a}$ & $\%$ & 23,53 & 58,82 & 17,65 & 100 & 33,19 \\
\hline & Kampung Bugis & $\mathrm{N}$ & 3 & 22 & 4 & 29 & 31,17 \\
\hline \multirow[t]{2}{*}{2.} & (Ex. Pelabuhan) & $\%$ & 10,35 & 75,86 & 13,79 & 100 & 36,81 \\
\hline & Penaruka & $\mathrm{N}$ & 10 & 22 & 4 & 36 & 25,41 \\
\hline \multirow[t]{3}{*}{3.} & $\mathrm{n}$ & $\%$ & 27,78 & 61,11 & 11,11 & 100 & 30 \\
\hline & Jumlah & $\mathbf{N}$ & 17 & 54 & 11 & 82 & 28,23 \\
\hline & & $\%$ & 20,73 & 65,86 & 13,41 & 100 & 100 \\
\hline
\end{tabular}

Berdasarkan Tabel 2. dapat diketahui perilaku masyarakat pesisir terhadap kebersihan pantai di 3 Kelurahan/Desa yaitu kelurahan Baktiseraga kategori rendah 23,53\%, sedang 58,82\%, dan tinggi 17,65\%. Pada Kelurahan Kp. Bugis kategori rendah 10,35\%, sedang 75,86\%, dan Tinggi 13,79\%. Kelurahan Penarukan dengan kategori rendah 27,78\%, sedang 61,11\%, dan tinggi 11,11\%. Secara umun perilaku masyarakat pesisir terhadap kebersihan pantai di Kota Singaraja terkategori sedang yaitu dengan capaian skor rata-rata sebesar 28,23.

Masyarakat pesisir banyak yang bermata pencaharian sebagai pedagang, anyak dari mereka yang sampahnya langsung dibuang ke pantai, masyarakat tidak memperdulikan dampak yang terjadi. Limbah yang paling sering terlihat yaitu limbah plastik dari pembungkus makanan, ada juga limbah dapur seperti sisa makanan, air sabun, sisa minyak yang langsung dibuang ke laut. Tindakan ini sudah mencemari lingkungan pantai walau masih dalam sekala kecil jika lama-kelamaan maka akan berdampak besar. Semakin baiknya mutu lingkungan disekitar pantai tergantung dari kemauan masyarakat pesisir berusaha menjaga dan merawat lingkungan pantai, secara tidak langsung pantai akan dikunjungi wisatawan.

Mayarakat masih membuang sampah ke pantai. Hal ini terjadi karena lebih mudah dan cepat jika membuang ke pantai, sehingga masyarakat pesisir cendrung membuang sampah ke pantai. Masyarakat belum mamatuhi peraturan yang ditetapkan pemerintah. Hal ini terjadi karena belum adanya sanksi yang tegas untuk membuat masyarakat jera dalam membuang sampah sehingga lingkungan pesisir menjadi kotor dan tercemar. Selain itu kurangnya sosialisasi dari pemerintah dalam memberikan pengarahan kepada masyarakat mengenai pentingnya menjaga lingkungan pesisir agar tetap bersih.

Kepedulian masyarakat pesisir terhadap lingkungan masih rendah. Banyak orang yang belum menyadari betapa pentingnya menjaga kebersihan. Ketidakdisiplinan juga terjadi pada masyarakat pesisir di Kota Singaraja yang kurang peduli terhadap lingkungan mengakibatkan kawasan sekitar pantai ikut tercemar.

\section{Hubungan Pengetahuan Masyarakat Pesisir terhadap Perilaku tentang Kebersihan Pantai Di Kota Singaraja}


Pengetahuan masyarakat pesisir bisa diperoleh dari pengalaman yang berasal dari berbagai macam sumber, seperti pendidikan formal, media massa, media elektronik, poster, buku petunjuk, petugas kesehatan, kerabat dekat, dan sebagainya. Sedangkan perilaku masyarakat pesisir terbentuk dari kebiasaan yang sering dilakukan oleh orang lain secara terus menerus hingga diapun ikut melakukannya. Kebiasaan yang banyak diikuti yaitu dalam penguasaan lahan pantai, tanpa memperdulikan keadaan lingkungan pantai yang semakin tercemar.

Terdapat atau tidaknya hubungan antara pengetahuan masyarakat pesisir dengan perilaku masyarakat pesisir terhadap kebersihan pantai di Kota Singaraja. Data ini dianalisis melalui korelasi product moment (Astawa, 2011). Kriteria dalam menguji hipotesis dengan analisis korelasi yaitu Ha diterima bila $r$ hitung lebih besar dari $r$ tabel $\left(r_{h}>r_{t}\right)$. Menurut tabel $r$ dari 82 adalah 0,220. Adapun pengujian Ha menggunakan rumus sebagai berikut:

$$
\begin{aligned}
& r_{x y}=\frac{n \sum x y-\sum x \sum y}{\sqrt{\left[\sum x^{2}-\left(\sum x\right)^{2}\left\lfloor n \sum y^{2}-\left(\sum y\right)^{2}\right]\right.}} \\
& r_{x y}=\frac{82.87976-3016.2348}{\sqrt{\left[82.114748-(3016)^{2}\left[82.70872-(2348)^{2}\right]\right.}} \\
& r_{x y}=\frac{7214032-7081568}{\sqrt{[9409336-9096256 \llbracket[5811504-5513104]}} \\
& r_{x y}=\frac{132464}{\sqrt{[313080 \llbracket[298400]}} \\
& r_{x y}=\frac{132464}{\sqrt{93423072000}} \\
& r_{x y}=0,433381924
\end{aligned}
$$

Berdasarkan perhitungan diatas maka diperoleh $r=0,433381924$. Selanjutnya jika dilihat pada tabel $r$ korelasi product moment maka diketahui $d f=n-2, d f=80$. Dilihat berdasarkan $r_{\text {tabel }}$ dengan taraf signifikasi $5 \%$ yaitu sebesar 0,220. Berarti $r_{\text {hitung }}=$ 0,433381924 dan $r_{\text {tabel }}=0,220$ dapat disimpulkan bahwa $r_{\text {hitung }}>r_{\text {tabel }}$ maka Ha diterima dan Ho ditolak. Berkenaan dengan ditolaknya Ho dan diterimanya Ha, maka dapat ditarik kesimpulan bahwa terdapat hubungan yang positif dan signifikan antara pengetahuan dengan perilaku masyarakat pesisir terhadap kebersihan lingkungan pantai di Kota Singaraja.

Pengetahuan bisa menjadi hal yang vital dalam mempengaruhi perilaku seseorang dalam menjaga mutu lingkungannya, sebab manusia akan menjadi semakin tahu dan sadar akan bahaya limbah yang dihasilkan terhadap lingkungannya. Pengetahuan yang dimiliki sekiranya juga berhubungan dengan perilaku masyarakat pesisir yang membuang sampahnya langsung ke laut. Baik buruknya perilaku masyarakat pesisir terhadap pantai kemungkinan tergantung seberapa baik pengetahuan dan juga pemahaman terhadap lingkungannya sendiri. 


\section{Simpulan dan Saran}

Berdasarkan hasil penelitian dan pembahasan yang telah diuraikan pada bab sebelumnya, dapat ditarik kesimpulan sebagai berikut: (1) Pengetahuan lingkungan masyarakat pesisir mengenai kebersihan disekitar pantai Kota Singaraja tergolong tinggi dengan diperolehnya skor rata-rata sebesar 36,85 dari 3 kelurahan yang menjadi sampel area. (2) Perilaku masyarakat pesisir terhadap kebersihan lingkungan pantai Kota Singaraja tergolong sedang dengan diperolehnya skor rata-rata sebesar 28,23. (3) Berarti karakteristik masyarakat pesisir yang ada di bagian timur, tengah, dan barat Kota Singaraja memiliki nilai pengetahuan dan perilaku yang sama dilihat dari hasil skor pada kuisioner pengetahuan dan perilaku. Menurut analisis korelasi product moment hasil $r=0,433381924$. Diketahui tabel $r$ korelasi product moment $d f=n-2, d f=80$. Berdasarkan $r_{\text {tabel }}$ dengan derajat kepercayaan 5\% yaitu sebesar 0,220. Berarti $r_{\text {hitung }}=$ 0,433381924 dan $r_{\text {tabel }}=0,220$ dapat disimpulkan bahwa $r_{\text {hitung }}>r_{\text {tabel }}$ maka Hipotesis diterima. Sehingga Terdapat hubungan positif dan signifikan antara pengetahuan lingkungan dengan perilaku masyarakat pesisir dalam menjaga kebersihan lingkungan

Saran yang disampaikan oleh peneliti yaitu: (1) Bagi masyarakat Kota Singaraja, diperlukan perubahan perilaku dalam membuang limbah langsung ke pantai. Jika upaya tersebut aktif dilakukan maka daya tarik pantai tersebut menjadi tinggi. Pantai akan banyak dikunjungi dan perekonomianpun meningkat. (2) Bagi pemerintah Kota Singaraja, agar senantiasa observasi ke wilayah pesisir. memberikan sosialisasi/penyuluhan terkait menjaga lingkungan pantai guna meningkatkan pengetahuan masyarakat. Diberikan sanksi yang tegas untuk masyarakat yang masih terlihat terang- terangan membuang sampah ke pantai/laut. Difasilitasi berupa bak sampah yang cukup atau penyediaan truk sampah di lokasi yang cukup dekat dengan permukiman masyarakat pesisir yang diangkut seminggu sekali, untuk memudahkan masyarakat pesisir membuang sampahnya. Karena tempat pembuangangan sampah yang jauh sering dijadikan alasan, maka jarak penyebaran bak sampah mohon di pertimbangkan agar lebih dekat.

\section{Ucapan Terimakasih}

Penelitian ini dapat diselesaikan berkat bimbingan dari berbagai pihak. Untuk ini pada kesempatan ini diucapkan terima kasih yang setulus-tulusnya kepada Rektor Universitas Pendidikan Ganesha, Dekan Fakultas Hukum dan Ilmu Sosial, Ketua Jurusan Pendidikan Geografi, staff dosen dii Jurusan Pendidikan Geografi, Pembimbing Akademik, Pembimbing 1, Pembimbing 2, Penguji 1, dan Penguji 2, Dinas-dinas pemerintahan di Kabupaten Buleleng, Dinas-dinas pemerintahan di Kecamatan Buleleng, Banyuwangi, Kepala kelurahan/ Desa yang ada di Kota Singaraja, Kelompok masyarakat pesisir yang ada di sepanjang pantai Kota Singaraja, Badan Pusat Statistik Kabupaten Buleleng, dan rekan-rekan mahasiswa Jurusan Pendidikan Geografi angkatan 2013. 


\section{Daftar Rujukan}

Arikunto, S. (2011). Prosedur Penelitian Suatu Pendekatan Praktik. Jakarta: Rineka Cipta. Astawa, I. B. M. (2011). Statistika Terapan untuk Penelitian. Singaraja: Jurusan Pendidikan Geografi FIS Undiksha.

Astono Widyo. (2010). Problem Sanitasi, Karakteristik Sosial Ekonomi dan Upaya Pemberdayaan Masyarakat. EKOSAINS, 1(2), 1-5.

Handoyo, Eko., dkk. (2015). Studi Masyarakat Indonesia. Yogyakarta: Ombak.

Hermawan dan Roesman. (2008). Perilaku Pedagang Sayur dalam Mengelola Kebersihan Lingkungan Hidup. Jurnal Bumi Lestari, 8(2).

Pinto Zulmiro. (2015). Kajian Perilaku Masyarakat Pesisiryang Mengakibatkan Kerusakan Lingkungan (Studi Kasus di Pantai Kuwaru, Desa Poncosari, KecamatanSrandakan, Kabupaten Bantul, Provinsi DIY). Wilayah Dan Lingkungan, 3(3), 163-174.

Rusdiana A. (2015). MEMBUMIKAN ETIKA LINGKUNGAN BAGI UPAYA MEMBUDAYAKAN PENGELOLAAN LINGKUNGAN YANG BERTANGGUNG JAWAB. Istek, 9(2).

Sriartha, I. P. (2004). Dasar-Dasar Metodelogi Penelitian Geografi. Singaraja: IKIP Negeri Singaraja.

Sukmadinata, N. S. (2011). Metode Penelitian Pendidikan. Bandung: Remaja Rosdakarya.

Wesnawa, I. G. A. (2010). Etika Lingkungan: Pelestari Fungsi Lingkungan (Perspektif Kearifan Lingkungan). Singaraja. 